\title{
GAMBARAN KANALIS MANDIBULARIS KIRI SECARA RADIOGRAFI PANORAMIK PADA WARGA MEDAN SELAYANG
}

\author{
(IDENTIFICATION OF LEFT MANDIBULAR CANAL USING PANORAMIC \\ RADIOGRAPHY AMONG MEDAN SELAYANG SUBJECTS)
}

\author{
Trelia Boel, Savena Bala Kumar \\ Departemen Radiologi Dental \\ Fakultas Kedokteran Gigi, Universitas Sumatera Utara \\ Jalan Alumni No.2, Kampus USU Medan 20155
}

\begin{abstract}
The aim of this study is to determine the variation of the propagation of the left mandibular canal through panoramic radiography among citizens in Medan Selayang sub-district. Radiography in dentistry plays a vital role in obtaining diagnostic information. The variation of the propagation of the mandibular canal can be seen through panaromic radiography image. This is very important for all dentist to conduct treatments, such as third molar surgery, implants and split ramus osteotomy. This research is a descriptive survey with cross-sectional approach was total sample 86 samples (men and woman) in Medan Selayang sub-district aged between $32-72$ years old. The results of this research showed that. The sample of citizens of Medan Selayang sub-district have normal left mandibular canal (100\%). In conclusion, there is no variation of the propagation of the left mandibular canal through panoramic radiography among citizens in Medan Selayang sub-district.
\end{abstract}

Key words: left mandibular canal, panoramic radiography

\begin{abstract}
Abstrak
Tujuan penelitian ini adalah untuk mengetahui gambaran kanalis mandibularis dan variasinya melalui radiografi panoramik pada warga di Kecamatan Medan Selayang. Radiografi dalam kedokteran gigi memainkan peran penting dalam memperoleh informasi diagnostik . Variasi penyebaran kanal mandibula dapat dilihat melalui gambar radiografi panaromik. Hal ini sangat penting bagi semua dokter gigi untuk melakukan perawatan, seperti operasi gigi molar ketiga, implan dan membagi ramus osteotomy. Jenis penelitian ini adalah survei deskriptif dengan pendekatan cross-sectional dengan 86 sampel, (laki-laki dan perempuan) di Kecamatan Medan Selayang berusia antara 32-72 tahun. Hasil penelitian menunjukkan yang memiliki kanal mandibula kiri normal 100\%. Sebagai kesimpulan, tidak terdapat variasi penjalaran kanalis mandibularis kiri pada masyarakat di Kecamatan Medan Selayang berdasarkan gambaran radiografi panoramik.
\end{abstract}

Kata kunci: kanalis mandibularis kiri, radiografi panoramik

\section{PENDAHULUAN}

Radiografi di bidang kedokteran gigi mempunyai peranan penting dalam memperoleh informasi diagnostik untuk penatalaksanaan kasus, mulai dari menegakkan diagnosis, merencanakan perawatan, menentukan prognosis, memandu dalam perawatan, mengevaluasi, dan observasi hasil perawatan. Radiografi di kedokteran gigi ada 2 macam yaitu radiografi intra oral (film di dalam mulut) dan radiografi ekstra oral (film di luar mulut). Radiografi ekstra oral merupakan pemeriksaan radiografi yang lebih luas dari kepala dan rahang dimana film berada di luar mulut. ${ }^{1}$ Radiografi ekstra oral yang paling sering digunakan dokter gigi adalah panoramik. $^{2}$

Kanalis mandibularis dapat dilihat dari gambaran radiografi dan jenis pemeriksaan radiografi yang paling sering dipakai adalah radiografi panoramik, Computed Tomography (CT) Scan dan Conventional Tomography. ${ }^{3}$ Jenis radiografi panoramik digunakan secara meluas karena mempunyai kelebihan dalam menyediakan gambaran kedua rahang secara keseluruhan dan dosis radiasi yang di- 
terima oleh individu rendah serta biaya yang harus dikeluarkan lebih rendah jika dibandingkan dengan Computed Tomography Scan dan Conventional Tomography. Jadi radiografi panoramik merupakan jenis radiografi yang paling banyak dipilih dalam melihat kanalis mandibularis. ${ }^{4}$

Kanalis mandibularis merupakan saluran dalam mandibula yang mengandung pembuluh darah dan saraf yang melewati gigi-gigi rahang bawah yaitu inferior alveolar neurovascular bundle..$^{5}$ Inferior alveolar neurovascular bundle terdiri atas inferior alveolar vein/veins, inferior alveolar artery/arteries, dan inferior alveolar nerve. ${ }^{6}$

Kanalis mandibularis ini bermula dari foramen mandibula pada bagian medial ramus. Kanalis ini berjalan dalam arah ke bawah dan ke depan dalam ramus dan kemudian secara horisontal dalam body of mandible sampai foramen mentale. ${ }^{6}$

Kanalis mandibularis mempunyai beberapa variasi diantaranya lokasi kanalis mandibularis dari apeks molar, variasi bentuk anatomis yaitu bifid mandibular canal, trifid mandibular canal, anterior loop/ incisive branch of the mandibular canal. Pada umumnya kanalis mandibularis adalah normal yaitu kanalis ini berjalan dalam arah ke bawah dan ke depan dalam ramus dan kemudian secara horisontal dalam body of mandible sampai foramen mentale. Apabila terdapat variasi, paling umum diketemui bifid kanalis mandibularis. Menurut Sanchis dkk., bifid mandibular canal terjadi apabila batas kortikal di sekeliling kanalis bergabung dan membentuk pulau tulang segitiga dimana puncaknya pada titik penyimpangan kanalis mandibularis. Nortje dkk. mengatakan bifid mandibular canal terbentuk bila terdapat penyimpangan di sepanjang kanalis mandi-

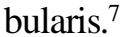

Banyak penelitian telah dilakukan untuk mendeteksi bifid mandibular canal melalui gambaran radiografi panoramik dan foto Computed Tomography Scan. Pada tahun 1973, Patterson dan Funke menggunakan radiografi panoramik dan lateral rahang, untuk mengidentifikasi kasus bifid mandibular canal unilateral dengan dua foramen mentale. ${ }^{8}$ Penelitian Nortje dkk. melaporkan insidens bifid mandibular canal sebanyak 0,9\% melalui gambaran panoramik. Grover dan Lorton melaporkan insidens bifid mandibular canal sebanyak $0,08 \%$ dari kalangan 5000 tentera US dengan mengunakan radiografi panoramik. Langlais dkk. melaporkan insidens bifid sebanyak (57 kasus) 0,95\% dari 6000 gambaran panoramik rutin pasien. Zografos dkk. melaporkan 3 kasus bifid mandibular canal dari 700 gambaran radiografi panoramik. Sanchis dkk. mendapat insidens bifid mandibular canal sebanyak 0,35\% dari analisis gambaran radiografi panoramik. ${ }^{9}$
Namun jika diperiksa melalui foto Computed Tomography Scan, Kuribayashi dkk. mendapat insidens bifid mandibular canal sebanyak 15,6\%.7 Pada tahun 2009 pula Naitoh dkk. melakukan penelitian dengan menggunakan Cone Beam Computed Tomography dan mendapat laporan $65 \%$ dengan insidens bifid mandibular canal. Karamifar dkk. melaporkan dua kasus insidens bifid mandibular canal dengan analisa gambaran radiografi panoramik. ${ }^{9}$

\section{BAHAN DAN METODE}

Jenis penelitian ini adalah penelitian deskriptif. Kriteria inklusi sampel adalah masyarakat Medan Selayang yang berumur 32-72 tahun dan kriteria eksklusi tidak pernah mengalami fraktur rahang bawah. Sampel berjumlah 86 orang. Wawancara, dilakukan pada sampel setelah itu mengisi informed consent dan kemudian dibawa ke Laboratorium Pramita untuk dilakukan pembuatan radiograf panoramik. Hasil radiografi tersebut dianalisa oleh ahli radiologi.

Data yang diperoleh diedit dan diolah dengan meggunakan program komputer. Analisis data digunakan analisis chi-square.

\section{HASIL}

Hasil penelitian menunjukkan bahwa semua mempunyai kanalis mandibularis kiri adalah normal $(100 \%)$.

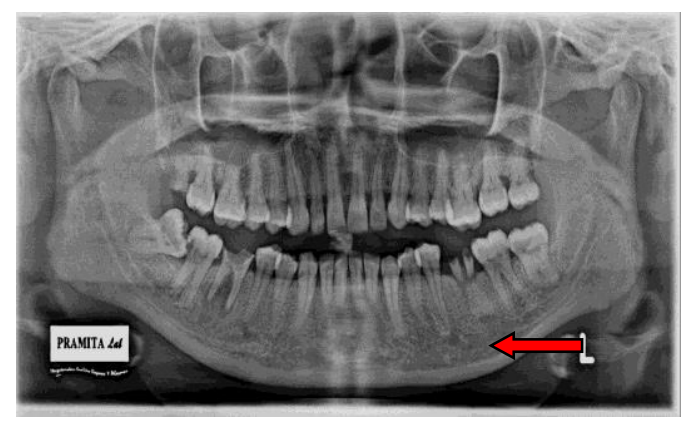

Gambar 1. Gambaran radiografi panoramik kanalis mandibularis kiri yang normal

\section{PEMBAHASAN}

Pada penelitian ini diperoleh hasil, yaitu tidak terdapat variasi penjalaran kanalis mandibularis kiri pada masyarakat di kecamatan Medan Selayang. Prevalensi kanalis mandibularis kiri yang normal pada masyarakat kecamatan Medan Selayang adalah sebesar 100\% dari 43 sampel, bila dibandingkan dengan penelitian sebelumnya Nortje dkk. yaitu dari total 3612 sampel diperoleh 0,9\% bifid mandibular 
canal. Grover dan Lorton dari 5000 sampel diperoleh $0,08 \%$ bifid mandibular canal, Langlais dkk. dari 6000 sampel diperoleh $0,95 \%$ bifid mandibular canal, Zografos dkk. dari 700 sampel diperoleh $0,43 \%$ bifid mandibular canal, Sanchis dkk. dari 2012 sampel diperoleh 0,35\% bifid mandibular canal dan Naitoh dkk. dari 212 sampel diperoleh $65 \%$ bifid mandibular canal.

Kanalis mandibularis pada umumnya adalah normal sesuai dengan teori, apabila terjadi variasi yang dilaporkan adalah bifid kanalis mandibularis dan prevalensinya secara umum kecil. Selain itu, untuk mengetahui ada tidaknya bifid kanalis mandibularis melalui radiografi panoramik konvensional juga mempunyai keterbatasan. Untuk mendapatkan hasil yang akurat tentu akan lebih baik bila menggunakan radiografi gambaran tiga dimensi contohnya Cone Beam Computed Tomography (CBCT).

Kesimpulan hasil penelitian yang telah dilakukan tidak terdapat variasi penjalaran kanalis mandibularis kiri pada masyarakat di Kecamatan Medan Selayang berdasarkan gambaran radiografi panoramik. Tidak ada variasi penjalaran kanalis mandibularis kiri terhadap rahang bawah pada masyarakat di Kecamatan Medan Selayang.

\section{Daftar Pustaka}

1. Boel T. Dental radiografi: Prinsip \& teknik. Medan: USU Press. 2009: 20
2. Alfaleh L. Panoramic Radiografi. http://faculty. ksu.edu.sa/16172/Documents/panoramic\%20radiography.pdf (July_12.2012).

3. Anonymous. Comparison of panoramic radiography, CT and conventional tomography in locating the mandibular canal before BSSO. Herkules.oulu.fi/isbn9514267508/html/x1275.html (July 11.2012).

4. Rashid SA, Ali J. Morphometric analysis of mandibular canal course and position in relation to gender and age of Iraqi sample using digital panoramic imaging. J Bagh College Dentistry 2011; 23: 93.

5. Anonymous. Mandibular canal.http://www.meriam webster.com/medical/mandi bular\%20canal (July 12.2012)

6. Juodzbalys. Anatomi of mandibular vital structures. Part I: Mandibular Canal and Inferior Alveolar Neurovascular Bundle In Relation with Dental Implantology. J Oral and Maxillofacial Research 2010; $1: 2$.

7. Anonymous. Bifid Mandibular Canal.http://repository.usu.ac.id/bitstream/123456789/32818/5/ Chapter\%20I.pdf (July 13.2012).

8. Karamifar K, Shahidi S, Tondari A. Indian Bilateral bifid mandibular canal: Report of two cases. Indian J Dent Res 2009; 20: 235.

9. Rashid SA, Ali J, Al-Nakib L. Identification of bifid mandibular canals among Iraqi subjects using panoramic imaging system. J Bagh College Dentistry $2011 ; 23(4): 79$. 